\title{
Young adult motor, sensory and cognitive outcomes and longitudinal development after very and extremely preterm birth
}

\begin{tabular}{|c|c|}
\hline Journal: & Neuropediatrics \\
\hline Manuscript ID & neuped-10-2018-2056-RA.R1 \\
\hline Manuscript Type: & Review Articles \\
\hline $\begin{array}{r}\text { Date Submitted by the } \\
\text { Author: }\end{array}$ & $n / a$ \\
\hline Complete List of Authors: & $\begin{array}{l}\text { Vollmer, Brigitte; University of Southampton, Clinical Neurosciences, } \\
\text { Faculty of Medicine; Karolinska Institutet, Department of Women's and } \\
\text { Children's Health } \\
\text { Stålnacke, Johanna; Stockholm University, Department of Psychology }\end{array}$ \\
\hline Keyword: & $\begin{array}{l}\text { preterm birth, neuromotor, cognitive, executive function, adulthood, } \\
\text { longitudinal development }\end{array}$ \\
\hline \multirow[t]{2}{*}{$\begin{array}{l}\text { Please select the subject area } \\
\text { of your manuscript: : }\end{array}$} & Developmental Neurology \\
\hline & $\begin{array}{l}\text { In this narrative review, we report on adult outcomes after very (before } \\
32 \text { week of gestation) and extremely (before } 28 \text { weeks of gestation) } \\
\text { preterm birth, with a focus on neuromotor function, neurosensory } \\
\text { impairment, general cognitive abilities, executive function, and } \\
\text { attentional abilities, all of which are important for academic progress, } \\
\text { peer relationships, and participation. Longitudinal development from } \\
\text { childhood to adulthood is described. } \\
\text { Preterm born individuals have a higher risk for impairment of general } \\
\text { cognitive abilities, executive function, attention, and neuromotor abilities } \\
\text { well into adulthood, with, however, considerable variability in outcomes. } \\
\text { Differences between individuals born preterm and their term born peers } \\
\text { persist. Long term outcomes of general cognitive ability can be predicted } \\
\text { with some degree of certainty from childhood assessments: those who } \\
\text { perform poor on early childhood age assessments very likely will not } \\
\text { catch up, whereas those who perform within the normal range on early } \\
\text { assessments sometimes accelerate their development relative to term } \\
\text { born peers. This appears similar for executive function and attention, } \\
\text { although data on trajectories for these functions are somewhat } \\
\text { inconsistent. In adulthood, some studies describe poorer educational } \\
\text { outcomes, employment, independent living, and/or economic situation } \\
\text { compared to term born individuals, however large proportion of those } \\
\text { born preterm report similar self-perceived quality of life. }\end{array}$ \\
\hline
\end{tabular}

\section{SCHOLARONE \\ Manuscripts}




\title{
Young adult motor, sensory and cognitive outcomes and longitudinal development after very and extremely preterm birth
}

\author{
Brigitte Vollmer ${ }^{1,2}$, Johanna Stålnacke ${ }^{3}$ \\ ${ }^{1}$ Clinical Neurosciences, Clinical and Experimental Sciences, University of Southampton; \\ Neonatal and Paediatric Neurology, Southampton Children's Hospital, Southampton, UK \\ 2Department of Women's and Children's Health, Karolinska Institutet, Stockholm, Sweden \\ ${ }^{3}$ Department of Psychology, Stockholm University, Stockholm, Sweden
}

\author{
Authors' addresses: \\ Brigitte Vollmer, Clinical Neurosciences, Southampton General Hospital, CG79, \\ Southampton SO16 6YD, UK \\ Johanna Stålnacke, Department of Psychology, Stockholm University, Stockholm SE-106 91, \\ Sweden
}

Corresponding author: Brigitte Vollmer, Clinical Neurosciences, Southampton General Hospital, CG79, Southampton SO166YD, UK. Email: b.vollmer@soton.ac.uk

Running title: Adult outcomes of preterm birth

\author{
Word count: 5456
}

Number of references: 70 


\begin{abstract}
In this narrative review, we report on adult outcomes after very (before 32 week of gestation) and extremely (before 28 weeks of gestation) preterm birth, with a focus on neuromotor function, neurosensory impairment, general cognitive abilities, executive function, and attentional abilities, all of which are important for academic progress, peer relationships, and participation. Longitudinal development from childhood to adulthood is described.

Preterm born individuals have a higher risk for impairment of general cognitive abilities, executive function, attention, and neuromotor abilities well into adulthood, with, however, considerable variability in outcomes. Differences between individuals born preterm and their term born peers persist. Long term outcomes of general cognitive ability can be predicted with some degree of certainty from childhood assessments: those who perform poor on early childhood age assessments very likely will not catch up, whereas those who perform within the normal range on early assessments sometimes accelerate their development relative to term born peers. This appears similar for executive function and attention, although data on trajectories for these functions are somewhat inconsistent. In adulthood, some studies describe poorer educational outcomes, employment, independent living, and/or economic situation compared to term born individuals, however large proportion of those born preterm report similar self-perceived quality of life.
\end{abstract}

Keywords: preterm birth, neuromotor, cognitive, executive function, adulthood, longitudinal development 
Approximately $11 \%$ of all live births worldwide are preterm with preterm birth rates continuing to increase and at the same time mortality in the context of preterm birth decreasing. ${ }^{1}$ It is well known that preterm birth, in particular very ( $<32$ weeks of gestation, wGA) and extremely preterm birth $(<28 \mathrm{wGA})$, is associated with risk for long-term neurological and developmental impairment. For a number of preterm cohorts adult outcomes have now been described cross-sectionally, and for some of the cohorts development from infancy to adulthood has been characterised. Longitudinal development, and identifying early predictors, of general and specific cognitive abilities, including executive functions, and attention abilities which are crucial for academic progress and socio-emotional functioning, is of particular interest. Knowledge about developmental trajectories, on a group level and on an individual level, will allow definition of particular subgroups who benefit from enhanced surveillance and early intervention. In addition, it will improve early counselling.

The aim of this narrative literature review is to summarise results of selected studies that have examined neuromotor function, neurosensory impairment, general cognitive abilities, executive function, and attentional abilities at adult age, and to present data on trajectories for these outcomes from early age to adulthood in individuals born very or extremely preterm. It is acknowledged that there is emerging information on socio-emotional, psychiatric, and somatic adult outcomes of very and extremely preterm birth, however this is beyond the scope of this review.

\section{Neuromotor function and development of neuromotor function into adulthood}

There are surprisingly little data on adult rates of severe neuromotor impairment (Cerebral Palsy, CP) in reports from cohort studies of very or extremely preterm born individuals. 
However, it is clear that preterm birth poses a risk for CP and that this is inversely related to the degree of immaturity at birth.

Birth registry data from Norway on all births from 1967 -1983, looking at adult CP rates (age 20 -36 years at time of study), report a CP prevalence in relation to gestational age of $9.1 \%$ for the 22-27 wGA group, $6 \%$ for the 28-30 wGA group, 1.9\% for the 31-33 wGA group, and $0.3 \%$ for the $34-26$ wGA group, compared with $0.1 \%$ for those born at term age. ${ }^{2}$ This is not significantly different from the Norwegian registry data for subsequent birth years (1967-2001) for which Trønnes et al, 2014, ${ }^{3}$ report CP rates (at age 13 years and older) in relation to gestational age of $8.5 \%$ in the $23-27$ wGA group, $5.6 \%$ at $28-30$ wGA group, $2.0 \%$ at $31-33$ wGA, $0.4 \%$ at $34-36$ wGA, and $0.1 \%$ for term age. In contrast, recent data from the Surveillance of Cerebral Palsy in Europe (SCPE) show that the prevalence of severe neuromotor impairment, i.e. Cerebral Palsy, has been decreasing over the time period 1980 to 2003. ${ }^{4}$ A decrease was seen for the normal birth weight group $(>2500 \mathrm{~g})$, and also a significant decrease for preterm born children with moderately low (1500 to $2499 \mathrm{~g}$ ) or very low (1500 to $2499 \mathrm{~g})$ birth weight (BW), with an indication of a decreasing trend even in those with extremely low $(<1000 \mathrm{~g})$ BW. ${ }^{4}$ Similar findings were reported by the Australian CP Register for the birth years 1993-2006. ${ }^{5}$ Whilst the Norwegian Birth Registry data and the $\mathrm{CP}$ registry data appear to be somewhat contradictory, this is most likely explained by methodological issues.

Information on $\mathrm{CP}$ rates at adult age from prospective longitudinal studies in preterm cohorts are available, for example, from the Helsinki Study of Very Low Birth Weight Adults $(<1500$ g; born $1978-1985$, assessed age $18-27$ years $)$, which reported a prevalence of $6 \% .^{6}$ For the Ontario Extremely Low Birth Weight cohort (BW 501 - 1000 g; born 1977-1982, assessed at age 22-25 years), Saigal et al, 2006, ${ }^{7}$ reported a CP rate of $13.7 \%, 20 \%$ of those having non-ambulatory $\mathrm{CP}$. The participants of these cohorts were, of course, born before 
antenatal steroids and surfactant were routinely used in clinical practice. For most single centre or population based cohorts that were born after the introduction of antenatal steroids and surfactant, CP rates have been described at school age, and one can, to a certain degree, infer from these data on adult CP rates. Severe neuromotor impairment (CP) can be reliably be diagnosed and/or confirmed in early childhood and it is not expected that a confirmed diagnosis of $\mathrm{CP}$ or overall functional level of impairment will change during individual development into adulthood. Therefore, $\mathrm{CP}$ rates in adult cohorts would not be expected to be different from those in the same cohort established at childhood age.

At school age, CP rates reported for the EPIPAGE study (population based study in France of children born 22-32 wGA in 1997) were $9 \%$ overall, with higher rates in the most immature group ( $18 \%$ in those born $24-25$ wGA, and $2 \%$ in those born at 32 wGA); $19 \%$ of those had severe (defined as non-ambulatory) CP. ${ }^{8,9}$ For children born extremely preterm, the EPICure study (a population based study of a cohort born at 25 or fewer completed wGA, born in 1995 in the United Kingdom and Ireland), at school age, $12 \%$ had CP, and $54 \%$ of those with CP had severe CP (defined as Gross Motor Function Classification Scale level above 3). ${ }^{10,11}$ The $\mathrm{CP}$ rate of $12 \%$ is not significantly different from that reported for the second recruitment phase of the EPIcure study (children born in the year 2006, <27 wGA), which established a $\mathrm{CP}$ rate of $14 \%$. However, the rate of severe CP (GMFCS $>3$ ) was $35 \%$ and thus lower than in the 1995 cohort. ${ }^{11}$ Slightly lower CP rates are reported for the Swedish EXPRESS cohort, a nationwide cohort of Swedish children born before 27 wGA 2004 - 2007, with a CP rate at age 6.5 years of $9.5 \% .^{12}$

Synnes et al, 2017, ${ }^{13}$ reported on a Canadian prospective national cohort study of children born $<29$ wGA between 2009 and 2011, and reported CP rates of 6.4\% (approximately 20\% of those had non-ambulatory $\mathrm{CP}$ ) at age 21 months. Considering that mild $\mathrm{CP}$ might still be 
undiagnosed at this early age and the rate of $\mathrm{CP}$ in this cohort at school age therefore might be a little higher, overall the data are in accordance with the EPIPAGE, EPIcure, and EXPRESS cohort data.

Cheong et al, 2017, ${ }^{14}$ reported CP rates for the Victorian Infant Collaborative Study cohort of $11-14 \%$ in children born extremely preterm (22-27 wGA) in three eras of recruitment, 19911992; 1997; and 2005, with no significant change over time in CP rates and also in the proportion of those with moderate-severe $\mathrm{CP}(6-7 \%)$. These data, and the data from the two EPIcure cohorts, are consistent with the SCPE and Australian CP Register data, which do not (yet) show a decreasing prevalence of $\mathrm{CP}$ in the extremely low birth weight group. It will be interesting to see how $\mathrm{CP}$ rates for the prospective population based cohorts of extremely preterm born children and adults develop over time for future recruitment eras.

Relatively little information on adult age outcomes is currently available on minor neurological signs and neuromotor function in the absence of CP. This has been described mainly for school age cohorts. Broström et al, 2018, ${ }^{15}$ in accordance with other studies that looked at slightly more mature cohorts, for example, the EPIPAGE cohort assessed at age 5 years, ${ }^{16}$ did show a higher prevalence of minor neurological dysfunction (assessed with a simplified version of the Touwen examination) at school age for a regional cohort of extremely preterm $(<27$ wGA) born children compared to the term born controls. In addition, a meta-analysis by DeKieviet et al, 2009, ${ }^{17}$ did show persisting poorer neuromotor function throughout childhood and into adolescence in very low birthweight and very preterm children compared to term born children.

Husby, et al, 2013, ${ }^{18}$ compared a very low BW cohort at age 23 years to term born controls, using the Grooved Pegboard test, Trail Making Test-5, Movement Assessment Battery for Children-2 (Movement ABC-2), and High-level Mobility Assessment Tool (HiMAT). They 
found differences in all measures between the very low BW and the term born normal BW controls, with motor speed being a particular problem for the very low BW participants. This cohort had previously been assessed at age 14 years, and the difference in gross and fine motor co-ordination did not change significantly between these two time points. They also found an association between impaired motor skills and mental health as well as health related quality of life. ${ }^{19}$ Poole et al, 2015, ${ }^{20}$ described adult motor co-ordination outcomes at ages 22-26 and 29-36 years for the Ontario cohort, a population-based birth cohort of extremely low BW survivors born between 1977 and 1982 in Ontario, Canada. They used the Adult Developmental Coordination Disorders/Dyspraxia Checklist, a self-report questionnaire that measures retrospectively childhood functional difficulties across different domains arising as a consequence of poor motor skills. They also used the Young Adult SelfReport Scale that measures, amongst other things, motor behaviours and competencies; neurosensory impairments (CP, visual, hearing impairment) were controlled for in the analysis. Significant differences were seen between the extremely low BW and the normal birth weight group at both ages. In addition, findings remained stable from assessments in childhood at age 8 years into adulthood, although it has to be kept in mind that different instruments were used at age 8 years (Bruininks-Oseretsky Test of Motor Proficiency; Vineland Adaptive Behavior Scales).

The information on adult neuromotor outcomes in the absence of CP is mainly based on information from cohorts who were born before the antenatal steroid and surfactant era. More studies are needed for the adult age and it remains to be seen whether over time a similar trend as for CP rates occurs.

\section{Hearing and visual impairment}


There is relatively little information available on hearing and visual outcomes for adult age specifically. Similar to neuromotor outcomes, this has mainly been reported for school age. A national register study of all live-born infants in Finland 1991-2008, including 1,018 256 participants, investigated the incidence of hearing impairment, visual impairment or blindness, and ROP according to gestational age. ${ }^{21}$ Three gestational age groups were defined, $<32$ wGA (very preterm), 32- 33 + 6 wGA (moderately preterm), 34-36 + 6 wGA (late preterm), and $\geq 37$ wGA. Keeping in mind that diagnoses were made in early childhood and up to school age only, this large study nevertheless provides relevant information in the context of long term outcomes. Preterm birth across the preterm gestational age range did pose a risk for visual impairment. Very and late preterm birth, but not moderate preterm birth, posed a risk for hearing impairment. The study did show that the prevalence of hearing and visual impairment (with or without a history of retinopathy of prematurity) is inversely related to immaturity at birth, with extremely preterm/low BW posing the highest risk, even after adjusting for relevant background factors.

With regards to visual impairment, prevalences for blindness range from $7 \%-9 \%$ (extremely preterm birth) to around $0.5-2 \%$ (very preterm birth). ${ }^{22,23,7,24}$ For extremely preterm populations, the Swedish EXPRESS study reports ophthalmological problems at age 6.5 years in $37.9 \%$ of the preterm children, compared to $6.2 \%$ of the term born controls, with blindness in $2.1 \%$, and visual impairment according to World Health Organization criteria in $4.8 \%$ of the preterm children. Strabismus was present in $17.4 \%$, and refractive errors in 29.7\%. Interestingly, no significant associations between GA at birth and visual impairment were seen when treatment-requiring ROP was adjusted for; in contrast, an association remained between refractive errors and GA at birth. ${ }^{25}$ Adult (age 19 years) outcome data for the EPIcure cohort ${ }^{26}$ show that extremely preterm birth influences fovea maturation and 


\section{General cognitive abilities and executive function}

Although variability in outcome is large, the majority of children born very or extremely preterm present at least subtle dysfunctions that impact cognitive abilities, educational outcome and behaviour. ${ }^{30,31}$ IQ is a global measure of cognitive function and is predictive of educational attainment and life adjustment. Level of IQ affects, as well as is the result of, development of a range of cognitive skills. Investigation into the effect of preterm birth on attention, language, and executive skills related to general cognitive ability has increased our knowledge into more specific weaknesses and areas of concern warranting monitoring and interventions. The more specific skills and abilities are measured using cognitive tasks of attention and executive function, ratings of scholastic abilities (i.e. mathematics, reading, spelling) and behaviour ratings of everyday function. Executive function has been identified as a particular area in which very and extremely preterm born individuals may develop problems. It refers to cognitive processes that are involved in goal-directed, self-regulation of emotion, thought and behaviour. Definitions and measurements of executive functions vary and comparisons are not always easily made. Typically executive function tasks include aspects of inhibition, working memory, cognitive flexibility, fluency and planning. Attention 
and mental speed are sometimes included under the executive function umbrella. In real life, executive function deficits manifest themselves, for example, in problems with socioemotional regulation, poor organizational and self-monitoring skills.

With regards to general cognitive ability, as measured by IQ, the majority of school-aged children born very or extremely preterm perform within the normal range, albeit on group level close to one standard deviation lower than term born peers, and this remains mainly unchanged when those individuals with $\mathrm{CP}$ are excluded from analyses. ${ }^{32,33,34}$ There is strong evidence from several large cohorts in different countries that this difference continues to persist throughout adolescence and into adulthood, with the largest difference in IQ compared to term born individuals observed in those born extremely preterm. ${ }^{24,35,36,37,38,39,40,41,42,43}$ Data from childhood and teenage age indicate that, in contrast to major neuromotor impairment, i.e. Cerebral Palsy, there has not been a significant change in cognitive/and or behavioural outcomes over time, with a negative correlation of measures of general cognitive ability and gestational age at birth across the preterm birth range. ${ }^{33}$ This has not significantly changed for those born in the era of prenatal steroids and surfactant. ${ }^{34}$

Executive function difficulties at school age, ${ }^{44}$ and, more recently, also at adolescent or adult age have been described for some of the large very or extremely preterm cohorts, with assessments based on questionnaires or test based performance. Overall, executive function difficulties are seen more frequently in individuals born very or extremely preterm than in their term born peers, and this occurs even in the context of general cognitive ability being in the normal range. ${ }^{45,46,47,48,49,50}$ Meta-analyses have established differences to term born children on measures of executive function of $0.3-0.6$ standard deviations in very preterm children $^{44,51}$ and cohort studies have found up to 1 standard deviation difference in extremely preterm children ${ }^{52}$. Similar to general cognitive ability, there is a correlation with immaturity at birth ${ }^{44}$, and associations with socio-economic status of the family ${ }^{47}$, and a number of 
various perinatal and neonatal risk factors, including preterm brain injury, have been described (see Taylor \& Clark, 2016, for review ${ }^{53}$ ).

\begin{abstract}
Attention
Attention abilities are often being assessed as part of executive function. However, studies specifically looking at attention deficits are available, and there is strong evidence that very preterm and, in particular, extremely preterm children are at increased risk for difficulties with attention, and attention deficit hyperactivity disorder (ADHD) is diagnosed in a considerable proportion of very and extremely preterm children ${ }^{44}$, with an Odds Ratio of about 3 for a risk of ADHD diagnosis when compared to term born children, and highest risk for those born extremely preterm. ${ }^{54}$ Some studies report predominantly problems with inattention rather than hyperactivity; however, recent meta-analyses found an increased risk for difficulties in inattention or hyperactivity, or both combined. ${ }^{54,55}$ Several studies report adult outcomes and overall the risk for attention problems continues to persist into adolescence and adulthood. e.g. 56,57,58
\end{abstract}

\title{
Longitudinal characterisation
}

For some cohorts developmental trajectories into adulthood have now been characterised. Overall, the available data suggest that general cognitive ability, measured by IQ, is stable over time and that differences between preterm born and term born individuals persist over time. They also indicate that adult outcomes can be predicted with some degree of certainty from assessments in early childhood. This is less clear for executive function development and different studies report slightly different findings with regards to trajectories and stability over time. 
The Dutch Project On Preterm and Small for gestational age infants (POPS) has followed a large cohort of individuals born in 1983 at $<32$ wGA or with BW $<1500 \mathrm{~g}$ up to the age of 19 years, with assessments at ages 5, 9, 11, 14, and 19 years. They found that major disability rates (based on cognitive and neurosensory functioning defined according to WHO criteria) remained stable throughout childhood and into young adulthood, but that minor disability rates increased with age. ${ }^{27}$ At age 19 years, cognitive function as assessed with the Multicultural Capacity Test_-Intermediate Level, a computer based intelligence test, were in the normal range, but still $24 \%$ of the preterm individuals reported difficulties in education. Predictors of intelligence were parental education, birthweight, and gestational age. ${ }^{60}$

\begin{abstract}
Allin et al, 2008, ${ }^{36}$ report findings from a cohort of very preterm ( $<33$ wGA) born young adults, assessed for IQ, and, as part of the executive function system, phonological and semantic verbal fluency, at ages 15 years and 19.5 years. They found similar differences between the preterm and the term born control group at both ages, which is similar to other reports, but also a decrease over time of Full Scale and Verbal IQ in the preterm group. This was only seen in males; no deterioration was found in females. Semantic verbal fluency increased over time in the term born participants but not in the preterm participants, whereas phonological verbal fluency increased in both groups over time. Interestingly, neither gestational age, nor birthweight, or neonatal ultrasound findings were related to the observed changes in performance over time. The same cohort was examined previously at ages 8 and 15 years and a decrease in IQ in the preterms was also seen between these two time points, suggesting that in this cohort, on a group level, that a decline of general cognitive abilities over time occurred.
\end{abstract}


Eryigit Madzwamuse et al 2015, ${ }^{47}$ reported findings on IQ (measured with the Wechsler Adult Intelligence Scale) and executive function (assessed were selective attention, verbal inhibition, visual selectivity and attention, divergent thinking, and verbal processing) at age 26 years for the the Bavarian Longitudinal Study cohort of very preterm born individuals $(<32$ wGA or $\mathrm{BW}<1500 \mathrm{~g})$, and compared this to age 6 years. At 26 years there was still a difference between the preterm participants and the term born controls in IQ and all executive function areas assessed. The results pointed to the preterms having more global problems rather than specific executive function deficits in contrast to the term born controls in whom problems in only one or two specific cognitive functions were seen. Socio-economic status of the family had a significant effect on outcomes at age 26 years. Over time, the difference between groups for IQ remained, indicating that there was no catch-up in the preterm group. Furthermore, for the same cohort, Breeman et al, 2015, ${ }^{41}$ reported more stable general cognitive abilities over time in the very low BW/very preterm group (32 wGA or BW $<1500 \mathrm{~g}$ at birth) when measured at ages 5 months (cGA), 20 months (cGA), 4, 6, 8, and 26 years, than in the term born controls. The stability over time in the very low BW/very preterm group remained after adjusting for the family's socio-economic status. However, once those preterm participants with severe cognitive impairment had been excluded, there was no longer a difference in stability over time between the groups. This suggests that the predictive value of early assessments is strongest for those with severe cognitive impairment and that little change over time is expected in this subgroup. It also suggests that there are limitations to plasticity in brain development after preterm birth; this is consistent with previous work by Taylor et al, 2004, ${ }^{60}$ in a longitudinal study children with low and extremely low BW. This study did show that some catch up in cognitive performance and a moderating effect of environmental factors was observed in those born with very low BW and few neonatal risk factors, but not in those born extremely preterm and/or with more neonatal risk factors. 
Interestingly, in the study by Breeman et al, 2015, ${ }^{41}$ adult Full Scale IQ at age 26 years could be predicted fairly well from very early assessments (Griffiths Mental Development Scale; total developmental quotient) at age 20 months in the very low $\mathrm{BQ} /$ very preterm group, whereas for the term born controls predictive value of the 6 year assessment was best.

Similar to the Bavarian cohort, for the Stockholm Neonatal Project (SNP) cohort, where preterm participants (and $<1500 \mathrm{~g} \mathrm{BW}$ and $<37 \mathrm{wGA}$; the majority of which were born $<27$ wGA) and term born controls were assessed at age 5.5 and age 18 years, overall stability of IQ and executive function over time was seen, ${ }^{61,62}$ with developmental trajectories being fairly well established at pre-school age for the majority of the preterm born participants. Lundequist et al, $2015^{61}$ report that the extremely preterm group (22-27 wGA), performed poorest on all the cognitive tests, in particular on executive function tasks. Compared to results at age 5.5 years the effect had not diminished but rather strengthened over time. At age 18 years, young adults born very preterm, i.e. after 28 wGA, with appropriate BW and no perinatal complications, functioned like term-born, whereas extreme prematurity, intrauterine growth retardation, and neonatal complications were associated with poorer outcome in IQ and executive function. A person-oriented approach for determination of individual developmental trajectories was used by Stålnacke et al, 2015, ${ }^{62}$ for the SNP cohort to identify multivariate distinct cognitive profiles at ages 5.5 years and at age 18 years, and to investigate individual stability over time. They showed that, overall, performance at age 5.5 years was highly predictive of performance at age 18 years. However, when individual trajectories were examined, different patterns, depending on level of performance at age 5.5 years, emerged: those who performed low at young age did not improve or even deteriorated at age 18 years; those who had performed above the norm at young age, generally improved in relative performance, and for those who were around the norm at young age, half improved 
in relative performance and the other half did not or had increased problems. Individual cluster membership and movement between clusters could not conclusively be predicted by background variables, which points to the inter-individual variability in outcome even among individuals with similar medical background with regards to neonatal complications.

Overall, these findings on individual trajectories are consistent with the Bavarian Longitudinal Study group level data that indicate that, for those with severe impairment high stability in development of cognitive function can be expected, and that for those with normal or above normal cognitive abilities early in childhood, prediction of adult outcomes is more uncertain. With regards to executive function development, Stålnacke, et al, 2019, ${ }^{63}$ investigated developmental stability of two core executive function components, working memory and cognitive flexibility, in the extremely or very preterm born $(<32 \mathrm{wGA})$ in the SNP cohort. Using a multiple mediator structural equation model, they found that both components of executive function were highly stable over time. Development, however, followed slightly different pathways. Male sex, lower gestational age at birth, intrauterine growth restriction, and perinatal medical complications adversely affected executive function outcome, and these effects were apparent already in infancy, as reflected by Griffiths Mental Development Scale at 10 months (corrected age). Level of parental education had a positive effect on outcome, which was apparent by age 5.5 years

Linsell et al, 2018, ${ }^{43}$ reported longitudinal development of general cognitive ability for the participants of the EPICURE cohort, which is a study with focus on extreme preterm birth $(<26+5$ wGA at birth), with assessments at age $2.5,6,11$, and 19 years of age. General cognitive abilities were assessed with the Bayley Scales of Infant Development at 2.5 year, at ages 6 and 9 years with the Kaufman Assessment Battery for Children, and at 19 years with the Wechsler Abbreviated Scale of Intelligence. In this study, no significant improvement or 
deterioration over time was seen in the extremely preterm group, which, similar to the above mentioned studies in slightly less immature cohorts, indicates that also in extremely preterm born individuals general cognitive ability can be fairly well predicted from early assessments. Trajectories in the extremely preterm and the term born control group overall were similar, with, however, larger within individual variability and larger variability between individuals in the preterm group, with this pattern increasing over time. Maternal education (in both the preterm and the term born group), male sex, and neonatal brain injury influenced cognitive outcome. $^{43}$

Doyle et al, 2015, ${ }^{42}$ reported longitudinal findings from the Victorian Infant Collaborative study cohort (born $<28 \mathrm{w}$ GA or BW $<1000 \mathrm{~g}$ ), a slightly more mature cohort than that of the EPICure study. Participants were assessed with the Bayley Scales at age 2 years and then with the age appropriate version of the Wechsler Scales at ages 5, 8, and 18 years. The differences between extremely preterm and term born control group remained unchanged over time for both measures of general cognitive abilities and academic achievement. Social factors (social class and maternal education) had a stronger effect on outcomes at older age but were weaker than biological factors (postnatal steroids, neonatal intraventricular haemorrhage), which had an effect throughout age. No individual trajectories are reported for this cohort though. Longitudinal development from 8-18 years of age of executive function was investigated for this cohort by Costa et al, 2017, ${ }^{49}$ using the parental form of Behavior Rating Inventory of Executive Function (BRIEF), which looks at executive dysfunction at home, school, and in social situations. Overall, for the majority of the participants, stable executive function performance was observed. At both time points more than half of the participants were in the normal range on both scales, $12-19 \%$ had persistent, remitting, or late onset executive function difficulties. Sex, social class, and IQ had an effect 
on executive function development, and there was an association between academic performance and executive function development, with the typical group performing better in all academic areas (mathematics, reading, spelling), and the remitting group performing better in reading and spelling than the late onset or persisting group. This study highlighted that for some preterm born individuals, difficulties with executive function are transient, and for others there is a late onset of difficulties, which has implications for tailoring support at school.

Longitudinal development of attention problems and diagnosis of ADHD from childhood to adulthood has been studied for some of the cohorts. For example, for the Bavarian Longitudinal Study cohort of very preterm/very low BW individuals, Breeman et al, 2016, ${ }^{57}$ found between age 6 or 8 years and age 26 years a persisting difference in attention span and diagnosis of ADHD between the very preterm/very low BW group and the term born controls. Over time, for both groups attention span increased and attention problems decreased but while the term born individuals tended to outgrow their problems, the difficulties persisted for the preterm group. Once those with severe neurodisability were excluded findings remained unchanged at childhood age, but the differences between preterms and term borns were no longer seen in adulthood. Linsell et al, 2018, examined trajectories between age 6 years and age 19 years for extremely preterm individuals in the EPICure study, using the Strengths and Difficulties questionnaire. ${ }^{64}$ Scores for inattention and hyperactivity were persistently higher in the preterm group than the term born group. Trajectories over time were similar, however, a slight decline in inattention and hyperactivity symptoms from childhood to adulthood was seen in the preterm group, which is different to what was observed in the Bavarian Longitudinal Study cohort. 


\section{"Real life" implications at adult age}

There is a considerable variability in educational outcomes, employment, independent living, economic situation, and relationships. Some studies report similar self-perceived health, wellbeing, and quality of life (with however, lower self-reported resilience) as those reported for term born individuals, for example, Hack et al, $2007,{ }^{65}$ for a very low BW population born before the prenatal steroid and surfactant era, and Roberts et al, 2013, ${ }^{66}$ for an extremely preterm population born after the introduction of prenatal steroids and surfactant. In contrast, Hille et al, 2007, ${ }^{37}$ reported for the Dutch POPS cohort significantly lower educational attainment and employment rates compared with the Dutch population. Saigal et al, 2006, ${ }^{67}$ examined health related quality of life at adulthood in a cohort of extremely low BW and normal BW term born individuals (born 1977-1982), and found that although the preterm individuals reported significantly more limitations in mobility, cognition, and sensory function than term born individuals, there was no significant difference at young adulthood in self-perceived reported quality of life, even for those with disability. Similarly, in another study, Saigal et al, 2006, ${ }^{68}$ reported, once individuals with neurosensory impairment were excluded, no significant differences between extremely preterm born and term born individuals in educational outcomes, employment, living independently, being in a relationship or being parents. Kroll et al, $2017,{ }^{69}$ reported for a cohort very preterm adults at age 28-34 years (born 1979-1984), associations between executive function and functioning in work and in social domains, social adjustment, years in education, and employment status. This was independent of IQ, and also remained unchanged once those with CP and neurosensory impairments were excluded from the analyses. A recent population based study in Germany, ${ }^{70}$ assessing participation in young adults born extremely preterm (born 19971999), found lower frequency in participation in the areas of autonomy, relationships and community recreation in the preterm population when compared to term born peers. Physical, 
cognitive, psychological difficulties, or socio-economic status were related to one or both, limited participation in autonomy and relationships. Overall, there are currently inconsistent findings on adult age real life implications of cognitive and executive function deficits after preterm birth, and further research in contemporary populations is needed.

\section{Limitations of existing studies and implications for interpretation of the findings}

Some methodological issues need to be kept in mind in the interpretation of study findings and when comparing outcomes of different cohort. The majority of currently available information on adult outcomes of very or extreme preterm birth comes from cohorts who were born before prenatal steroids and surfactant were routinely used in clinical practice; in addition in the last couple of decades there have been further advances in perinatal and neonatal medicine that might affect long term outcome, and this is not yet reflected in the data that are currently available to us. Outcome data are generated from registers, single centre cohorts, or population based cohorts, which makes direct comparison difficult. In different studies, there are different proportions of very and extreme preterm individuals and different proportions of those born small for gestational age, which affects outcome data but often this is not reported separately; not always are outcome of those with neuromotor and/or neurosensory impairment analysed separately, and in some studies analyses are not controlled for all important biological and social factors. Finally, attrition bias is always a concern in follow-up studies that span decades.

\section{Conclusions}

Increasing numbers of individuals born very or extremely preterm survive without major neuromotor (Cerebral Palsy) or severe neurosensory impairment. However, even in the 
absence of major neuromotor impairment, there remains a significant risk for impairment in areas that are important for academic success, peer relationships, and participation, with a large variability in these outcomes. Early prediction of outcomes at adult age remains a challenge; however, available information suggests that there is stability over time with regards to general cognitive abilities, and probably also for executive functions and attention. Childhood assessments are predictive of adult general cognitive and executive function abilities to a certain degree: those that perform poorly in childhood are likely to continue to have significant difficulties, whereas those that perform within the normal range sometimes accelerate their developmental pace relative to term born peers. However, it is important to remember that adult outcomes cannot be predicted at birth or infancy, and that biological and/or social variable that affect outcome will take their toll early, others will be increasingly important in later years. 


\section{References}

1. Blencowe H, Cousens S, Chou D, et al. Born Too Soon Preterm Birth Action Group. Born too soon: the global epidemiology of 15 million preterm births. Reprod Health. 2013;10 Suppl 1:S2. Epub 2013 Nov 15. Review.

2. Moster D, Lie RT, Markestad T. Long-term medical and social consequences of preterm birth. N Engl J Med. 2008 Jul 17;359(3):262-73.

3. Trønnes H, Wilcox AJ, Lie RT, et al. Risk of cerebral palsy in relation to pregnancy disorders and preterm birth: a national cohort study. Dev Med Child Neurol. 2014 Aug;56(8):779-85.

4. Sellier E, Platt MJ, Andersen GL, et al. Surveillance of Cerebral Palsy Network. Decreasing prevalence in cerebral palsy: a multi-site European population-based study, 1980 to 2003. Dev Med Child Neurol. 2016 Jan;58(1):85-92.

5. ACPR. Report of the Australian Cerebral Palsy Register, Birth Years 1993-2006. 2013. Available on request to smcintyre@cerebralpalsy.org.

6. Kajantie E, Strang-Karlsson S, Hovi P, et al. Adults born at very low birth weight exercise less than their peers born at term. J Pediatr. 2010 Oct;157(4):610-6, 616.e1.

7. Saigal S, Stoskopf B, Streiner D, et al. Transition of extremely low-birth-weight infants from adolescence to young adulthood: comparison with normal birth-weight controls. JAMA. 2006 Feb 8;295(6):667-75.

8. Larroque B, Ancel PY, Marret S, et al. Neurodevelopmental disabilities and special care of 5-year-old children born before 33 weeks of gestation (the EPIPAGE study): a longitudinal cohort study. Lancet. 2008 Mar;371(9615):813-20. 
9. Beaino G, Khoshnood B, Kaminski M, et al. Predictors of cerebral palsy in very preterm infants: the EPIPAGE prospective population-based cohort study. Dev Med Child Neurol. 2010 Jun;52(6):e119-25.

10. Marlow N, Wolke D, Bracewell MA, et al. Neurologic and developmental disability at six years of age after extremely preterm birth. N Engl J Med. 2005 Jan 6;352(1):9-19.

11. Moore T, Hennessy EM, Myles J, et al. Neurological and developmental outcome in extremely preterm children born in England in 1995 and 2006: the EPICure studies. BMJ 2012; 345: e7961.

12. Serenius F, Ewald U, Farooqi A, et al. Neurodevelopmental Outcomes Among Extremely Preterm Infants 6.5 Years After Active Perinatal Care in Sweden. JAMA Pediatr. 2016 Oct 1;170(10):954-963.

13. Synnes A, Luu TM, Moddemann D, et al. Determinants of developmental outcomes in a very preterm Canadian cohort. Arch Dis Child Fetal Neonatal Ed. 2017 May;102(3):F235-F234.

14. Cheong JLY, Anderson PJ, Burnett AC, et al. Changing Neurodevelopment at 8 Years in Children Born Extremely Preterm Since the 1990s. Pediatrics. 2017 Jun;139(6). pii: e20164086.

15. Broström L, Vollmer B, Bolk J, et al. Minor neurological dysfunction and associations with motor function, general cognitive abilities, and behaviour in children born extremely preterm. Dev Med Child Neurol. 2018 Aug;60(8):826-832.

16. Arnaud C, Daubisse-Marliac L, White-Koning M, et al. Prevalence and associated factors of minor neuromotor dysfunctions at age 5 years in prematurely born children: the EPIPAGE Study. Arch Pediatr Adolesc Med. 2007 Nov;161(11):1053-61. 
17. de Kieviet JF, Piek JP, Aarnoudse-Moens CS, Oosterlaan J. Motor development in very preterm and very low-birth-weight children from birth to adolescence: a meta-analysis. JAMA. 2009 Nov 25;302(20):2235-42.

18. Husby IM, Skranes J, Olsen A, et al. Motor skills at 23 years of age in young adults born preterm with very low birth weight. Early Hum Dev.2013 Sep;89(9):747-54.

19. Husby IM, Stray KM, Olsen A, et al. Long-term follow-up of mental health, healthrelated quality of life and associations with motor skills in young adults born preterm with very low birth weight. Health Qual Life Outcomes. 2016 Apr 7;14:56.

20. Poole KL, Schmidt LA, Missiuna C, et al. Motor Coordination Difficulties in Extremely Low Birth Weight Survivors Across Four Decades. J Dev Behav Pediatr. 2015 Sep;36(7):521-8.

21. Hirvonen M, Ojala R, Korhonen P, et al. Visual and Hearing Impairments After Preterm Birth. Pediatrics. 2018 Aug;142(2). pii: e20173888.

22. Doyle LW, Casalaz D; Victorian Infant Collaborative Study Group. Outcome at 14 years of extremely low birthweight infants: a regional study. Arch Dis Child Fetal Neonatal Ed. 2001 Nov;85(3):F159-64.

23. Farooqi A, Hägglöf B, Sedin G, et al. Chronic conditions, functional limitations, and special health care needs in 10- to 12-year-old children born at 23 to 25 weeks' gestation in the 1990s: a Swedish national prospective follow-up study. Pediatrics. 2006 Nov;118(5):e1466-77.

24. Hack M, Flannery DJ, Schluchter M, et al. Outcomes in young adulthood for very-lowbirth-weight infants. N Engl J Med. 2002 Jan 17;346(3):149-57.

25. Hellgren KM, Tornqvist K, Jakobsson PG, et al. Ophthalmologic Outcome of Extremely Preterm Infants at 6.5 Years of Age: Extremely Preterm Infants in Sweden Study 
(EXPRESS). JAMA Ophthalmol. 2016 Mar 24. doi: 10.1001/jamaophthalmol.2016.0391. [Epub ahead of print].

26. Balasubramanian S, Beckmann J, Mehta H, et al. Relationship between Retinal Thickness Profiles and Visual Outcomes in Young Adults Born Extremely Preterm: The EPICure@19 Study. Ophthalmology. 2018 Aug 6. pii: S0161-6420(18)31543-4.

27. van der Pal-de Bruin KM, van der Pal SM, Verloove-Vanhorick SP, Walther FJ. Profiling the preterm or VLBW born adolescent; implications of the Dutch POPS cohort follow-up studies. Early Hum Dev. 2015 Feb;91(2):97-102.

28. Adams-Chapman I, Heyne RJ, DeMauro SB, et al. Follow-Up Study of the Eunice Kennedy Shriver National Institute of Child Health and Human Development Neonatal Research Network. Neurodevelopmental Impairment Among Extremely Preterm Infants in the Neonatal Research Network. Pediatrics. 2018 May;141(5). pii: e20173091.

29. Johnson S, Hennessy E, Smith R, et al. Academic attainment and special educational needs in extremely preterm children at 11 years of age: the EPICure study. Arch Dis Child Fetal Neonatal Ed. 2009 Jul;94(4):F283-9.

30. Aylward, GP. Methodological considerations in neurodevelopmental outcome studies of infants born prematurely. In C. Nosarti, R. M. Murray, \& M. Hack (Eds.), Neurodevelopmental outcomes of preterm birth. From childhood to adult life (pp. 164175). Cambridge: Cambridge University Press; 2010.

31. Howard K, Anderson PJ, Taylor, HG. Executive functioning and attention in children born preterm. In V. Anderson, R. Jacobs, \& P. J. Anderson (Eds.), Executive functions and the frontal lobes. A lifespan perspective (pp. 219-241). New York, NY:Psychology Press; 2008. 
32. Bhutta AT, Cleves MA, Casey PH, et al. Cognitive and behavioural outcomes of schoolaged children who were born preterm: a meta-analysis. JAMA.2002 Aug 14;288(6):72837.

33. Kerr-Wilson CO, Mackay DF, Smith GC, Pell JP. Meta-analysis of the association between preterm delivery and intelligence. J Public Health (Oxf). 2012 Jun;34(2):209-16.

34. Twilhaar ES, Wade RM, de Kieviet JF, et al. Cognitive Outcomes of Children Born Extremely or Very Preterm Since the 1990s and Associated Risk Factors: A Metaanalysis and Meta-regression. JAMA Pediatr. 2018 Apr 1;172(4):361-367.

35. Hack M. Adult outcomes of preterm children. J Dev Behav Pediatr. 2009 Oct;30(5):46070. Review.

36. Allin M, Walshe M, Fern A, et al. Cognitive maturation in preterm and term born adolescents. J Neurol Neurosurg Psychiatry. 2008 Apr;79(4):381-6.

37. Hille ET, Weisglas-Kuperus N, van Goudoever JB, Jacobusse GW, et al. Functional outcomes and participation in young adulthood for very preterm and very low birth weight infants: the Dutch Project on Preterm and Small for Gestational Age Infants at 19 years of age. Pediatrics. 2007 Sep;120(3):e587-95.

38. Strang-Karlsson S, Andersson S, Paile-Hyvärinen M, et al. Slower reaction times and impaired learning in young adults with birth weight $<1500$ g. Pediatrics. 2010 Jan;125(1):e74-82.

39. Løhaugen GC, Gramstad A, Evensen KA, et al. Cognitive profile in young adults born preterm at very low birthweight. Dev Med Child Neurol. 2010 Dec;52(12):1133-8.

40. Pyhälä R, Lahti J, Heinonen K, Pesonen AK, et al. Neurocognitive abilities in young adults with very low birth weight. Neurology. 2011 Dec 6;77(23):2052-60.

41. Breeman LD, Jaekel J, Baumann N, Bartmann P, Wolke D. Preterm Cognitive Function Into Adulthood. Pediatrics. 2015 Sep;136(3):415-23. 
42. Doyle LW, Cheong JL, Burnett A, et al. Biological and Social Influences on Outcomes of Extreme-Preterm/Low-Birth Weight Adolescents. Pediatrics. 2015 Dec;136(6):e1513-20.

43. Linsell L, Johnson S, Wolke D, et al. Cognitive trajectories from infancy to early adulthood following birth before 26 weeks of gestation: a prospective, population-based cohort study. Arch Dis Child.2018 Apr;103(4):363-370.

44. Aarnoudse-Moens CS, Weisglas-Kuperus N, van Goudoever JB, Oosterlaan J.Metaanalysis of neurobehavioral outcomes in very preterm and/or very low birthweight children. Pediatrics. 2009 Aug;124(2):717-28.

45. Luu TM, Ment L, Allan W, Schneider K, Vohr BR. Executive and memory function in adolescents born very preterm. Pediatrics. 2011 Mar;127(3):e639-46.

46. Heinonen K, Pesonen AK, Lahti J, et al. Self- and parent-rated executive functioning in young adults with very low birth weight. Pediatrics. 2013 Jan;131(1):e243-50.

47. Eryigit Madzwamuse S, Baumann N, Jaekel J, Bartmann P, Wolke D. Neuro-cognitive performance of very preterm or very low birth weight adults at 26 years. J Child Psychol Psychiatry. 2015 Aug;56(8):857-64.

48. Lundequist A, Böhm B, Lagercrantz H, et al. Cognitive outcome varies in adolescents born preterm, depending on gestational age, intrauterine growth and neonatal complications. Acta Paediatr. 2015 Mar;104(3):292-9.

49. Costa DS, Miranda DM, Burnett AC, et al. Executive Function and Academic Outcomes in Children Who Were Extremely Preterm. Pediatrics. 2017 Sep;140(3). pii: e20170257.

50. Kroll J, Karolis V, Brittain PJ, et al. Real-Life Impact of Executive Function Impairments in Adults Who Were Born Very Preterm. J Int Neuropsychol Soc. 2017 May;23(5):381389. 
51. Mulder H, Pitchford NJ, Hagger MS, Marlow N. Development of executive function and attention in preterm children: a systematic review. Dev Neuropsychol. 2009; 34(4):393421.

52. Farooqi A, Adamsson M, Serenius F, Hägglöf B. Executive functioning and learning skills of adolescent children born at fewer than 26 weeks of gestation. PLoS One. 2016; 11:e0151819.

53. Taylor HG, Clark CA. Executive function in children born preterm: Risk factors and implications for outcome. Semin Perinatol. 2016 Dec;40(8):520-529. doi:10.1053/j.semperi.2016.09.004. Epub 2016 Nov 8. Review. PubMed PMID: 27836424;PubMed Central PMCID: PMC5167660.

54. Franz AP, Bolat GU, Bolat H, et al. Attention-Deficit/Hyperactivity Disorder and Very Preterm/Very Low Birth Weight: A Meta-analysis. Pediatrics. 2018 Jan;141(1). pii:e20171645.

55. Mathewson KJ, Chow CH, Dobson KG, et al. Mental health of extremely low birth weight survivors: A systematic review and meta-analysis. Psychol Bull. 2017 Apr;143(4):347-383.

56. Hack M, Youngstrom EA, Cartar L, et al. Behavioral outcomes and evidence of psychopathology among very low birth weight infants at age 20 years. Pediatrics. 2004 Oct;114(4):932-40.

57. Breeman LD, Jaekel J, Baumann N, et al. Attention problems in very preterm children from childhood to adulthood: the Bavarian Longitudinal Study. J Child Psychol Psychiatry. 2016 Feb;57(2):132-40.

58. Van Lieshout RJ, Boyle MH, Saigal S, et al. Mental health of extremely low birth weight survivors in their 30s. Pediatrics. 2015 Mar;135(3):452-9. 
59. Weisglas-Kuperus N, Hille ETM, Duivenvoorden HJ, et al. Intelligence of very preterm or very low birth weight infants in young adulthood. Arch Dis Child Fetal Neonatal Ed 2009;94(3):196-F200.

60. Taylor, H.G., Minich, N.M., Klein, N., \& Hack, M. Longitudinal outcomes of very low birth weight: Neuropsychological findings. Journal of the International Neuropsychological Society, 2004;10, 149-163.

61. Lundequist A, Böhm B, Lagercrantz H, et al. Cognitive outcome varies in adolescents born preterm, depending on gestational age, intrauterine growth and neonatal complications. Acta Paediatr. 2015 Mar;104(3):292-9.

62. Stålnacke J, Lundequist A, Böhm B, Forssberg H, Smedler AC. Individual cognitive patterns and developmental trajectories after preterm birth. Child Neuropsychol. 2015;21(5):648-67.

63. Stålnacke J, Lundequist A, Böhm B, et al. A longitudinal model of executive function development from birth through adolescence in children born very or extremely preterm. Child Neuropsychol. 2019 Apr;25(3):318-335.

64. Linsell L, Johnson S, Wolke D, et al. Trajectories of behavior, attention, social and emotional problems from childhood to early adulthood following extremely preterm birth: a prospective cohort study. Eur Child Adolesc Psychiatry. 2018 Sep 7. doi: 10.1007/s00787-018-1219-8. [Epub ahead of print].

64. Hack M, Cartar L, Schluchter M, et al. Self-perceived health, functioning and well-being of very low birth weight infants at age 20 years. JPediatr. 2007 Dec;151(6):635-41, 641.e1-2. Epub 2007 Sep 4.

65. Roberts G, Burnett AC, Lee KJ, et al. Victorian Infant Collaborative Study Group. Quality of life at age 18 years after extremely preterm birth in the post-surfactant era. J Pediatr. 2013 Oct;163(4):1008-13.e1. 
66. Saigal S, Stoskopf B, Pinelli J, et al. Self-perceived health-related quality of life of former extremely low birth weight infants at young adulthood. Pediatrics. 2006 Sep;118(3):11408.

67. Saigal S, Stoskopf B, Streiner D, et al. Transition of extremely low-birth-weight infants from adolescence to young adulthood: comparison with normal birth-weight controls. JAMA. 2006 Feb 8;295(6):667-75.

68. Kroll J, Karolis V, Brittain PJ, et al. Real-Life Impact of Executive Function Impairments in Adults Who Were Born Very Preterm. J Int Neuropsychol Soc. 2017 May;23(5):381389.

69. Sell K, Rapp M, Muehlan H, et al. Frequency of participation and association with functioning in adolescents born extremely preterm - Findings from a population-based cohort in northern Germany. Early Hum Dev. 2018 May;120:67-73. 